\title{
Video Data Sensing
}

Working Post Qualitatively in Classroom Based Video Inquiry

\author{
Lucy Catherine Caton \\ Manchester Metropolitan University, UK \\ lucycaton2o@gmail.com
}

\begin{abstract}
This article situates at the interstice of post qualitative inquiry and child participatory video research, in responding to the need for more work around child, camera and researcher relations, where bodies (human and otherwise) coexist and agency is not bounded in one human subject. The article makes its contribution by describing affective methodologies for dealing with vast amounts of digital video data whilst displacing dominant framings for knowing children. The author offers the technique of Video data sensing (Caton, 2019) to recognise how child subjectivities emerge out of the movements and rhythms of bodies, formlessness and chaos. The technique works in conjunction with digital software, as a way for researchers and practitioners to move beyond simply labelling children and their capacities in new and alternate ways, as light, pattern, colour and texture become sites of knowledge production within the child and camera assemblage (Deleuze and Guattari, 1987/2014).
\end{abstract}

\section{Keywords}

visual methodology - child participatory inquiry - post-qualitative - post-human GoPro cameras - digital

This article considers what it means to engage post qualitatively in classroom based video inquiry, by resisting familiar framing practices when observing children. Despite substantial critique of dominant approaches to qualitative research methods from scholars of the post qualitative turn (St. Pierre 2013, MacLure, 2011, Pillow, 2003) one question that still remains under theorised is how we might go about or replace the practice of 'selecting' and 'analysing'

(C) LUCY CATON, 2019 | DOI:10.1163/23644583-00401001 | THIS IS AN OPEN ACCESS ARTICLE DISTRIBUTED UNDER THE TERMS OF THE CC-BY 4.O LICENSE. 
large quantities of digital video recordings. Building on the work of de Freitas (2015, 2016), St. Pierre (2013), and Holmes (2010) the paper describes the technique of 'video data sensing' (Caton, 2019), an approach to engaging with large quantities of video data that dislodges the role of the spectator and those familiar practices of 'looking' at children.

Video has become a common form of data for educational research, frequently employed to capture reality in a more convenient format. The paper moves away from representational understandings of children in classroom video, by taking up the challenge set by de Freitas $(2015,2016)$ to examine how video is materially implicated in the creation of knowledge. Furthermore, the paper explores how the nature of digital video functions to create new social, cultural and material relations at the thresholds of life (child / researcher) and machine (Go Pro camera and digital film).

The article is structured as follows. Firstly, I discuss post qualitative inquiry as it has emerged through the wider 'ontological turn' (Rosiek, 2013) in social sciences. This ontology signals a shift away from epistemology (knowing) where representational logic and human assumptions serve to organise the world towards an ontology of becoming (Deleuze and Guattari, 1987/2014). Deleuze and Guattari wrote in their original theorisation in regards to books and authors, "There is no longer a tripartite division between a field of reality (the world) and a field of representation (the book) and a field of subjectivity (the author) (1987/2014, p. 23). Such relational ontology, I draw on, to disrupt similar object / subject binaries between spectator and film, where we might re-think visual content without representation and where language and the practice of spectatorship assumes a different role (Holmes, 2010).

The following section, navigates through contemporary post qualitative studies involving children and video. I draw from this body of work to consider how digital recording equipment might function beyond simple tools to reproduce humanist narratives within classroom spaces. The key tenet of the paper is to put to work the practice of video data sensing (Caton, 2019) as a productive way to deal with vast quantities of video recordings. I demonstrate how looping video data out of direct view, opens up an alternative embodied and sensory engagement with the content. My intention is to demonstrate how resisting the temptation to interpret and code long sequences of film, according to its usefulness or not, becomes unproductive within a relational ontology, where matter and meaning coexist. As such, what emerges through an embodied and sensory engagement with hours of video footage, recorded by children in an after school club, is a series of interruptive still frames.

VIDEO JOURNAL OF EDUCATION AND PEDAGOGY 4 (2019) $\quad$ 1-22 
Video data sensing (Caton, 2019) operates in a two-fold manner that helps to create sites of knowledge in productively dealing with vast amounts of video footage. This sensory and embodied mode of engagement with the video operates beyond codification and interpretive ways we observe children. As such, I demonstrate how the source still frames work in conjunction with digital experiments to produce a 'haptic' (Marks, 2002) visualisation of classroom conformity. Inciting a 'haptic' visualisation, as I later discuss, opens up readings that go against the grain of 'any sense of spectators victory' where the children 'slip in and out of being camouflaged remaining incomplete as (bodies) contaminate spaces that were previously bounded and fixed' (Holmes, 2010, p. 30). I highlight, how video data sensing brings feelings and (re)collections to our looking practices that produce a very different response to straightforward readings of the images.

\section{$1 \quad$ Participatory Video Research (Un)Done}

The arguments of the paper address two problems. First, it contributes to the relatively few video-based studies working at the cross section of post qualitative inquiry and child participatory research that use DeleuzeGuattarian philosophies (1987/2014) as conceptual tools. In particular, few post qualitative, video-based studies utilise a GoPro camera and the resultant large quantities of film that result from continuous filming with a wearable camera. Secondly, there remains a need to experiment with and articulate practical approaches to productively deal with vast quantities of video whilst interrogating the hierarchal researcher 'gaze' within the video 'selection' and 'analysis' process.

Post qualitative inquiry is part of a wider change in philosophy and theory that some have called the 'ontological turn'. Rosiek (2013) describes this as having two key tenets. The first recognises a commitment to 'reflexive realism' and the latter asserts the use of an ontology of the future that serves as a guide to social inquiry. The 'ontological turn' signals a shift of focus away from epistemology (knowing) towards ontology that is being and the nature of reality. Post qualitative inquiry is understood in relation to posthumanism, because it does not assume that reality is socially constructed, or that the world only exists for and through human concerns. To this extent, new materialisms, new empiricism, Deleuzian philosophy and posthumanisms can all be situated within this broader 'ontological turn'.

The fundamental question throughout, is to imagine how post qualitative inquiry would understand data produced in child participatory video inquiry.

VIDEO JOURNAL OF EDUCATION AND PEDAGOGY 4 (2O19) $\quad$ 1-22 
To attempt this, I draw on the notion of 'assemblage' (Deleuze and Guatarri, 1987/2014) to recognise the world through inter-relations of bodies (human and otherwise). I theorise how cameras, film, sound, light and human subjectivities, mutually co-exist through performative, embodied and sensory modes of knowing rather than through representational interpretations of film content.

This has meant experimenting with ways to disrupt binary logic that elevate human (researcher and child) intentionality and knowledge over all other matter (camera and digital video). Attempting to think beyond human agency has been a critical factor, which has provoked recognition of the 'other-than-human' and 'more-than-human' (Taylor and Hughes, 2016). I write and think with GoPro cameras, digital film, sound, light, colour in a complex arrangement with human beings. However, the challenge has been to observe what these disparate and overlapping relations might 'look' like and the value in recognising what comes to matter through such relations. I foreground Deleuze and Guattari's (1987/2014) philosophies to recognise processes, events and bodies as 'assemblages', in which potential is created through their coming together-ness and not in the individual entities (human or machine) qualities and functions.

Video data sensing (Caton, 2019) is one response that operates to emphasise the unfolding nature of 'doing' video research, where knowledge remains detached from accounts of subject-driven-agency. Approaches to experimenting with the video emerged, within my doctoral study, as a practical response to deal with quantities of footage produced when children recorded their experiences in an afterschool club, using a digital GoPro camera. I set out to dislocate the process of direct spectatorship of the video footage produced in order to provoke a new manner of engagement with the content. Through frequent trial and experimentation with extended sequences of digital video, I attempted to apply interruptive techniques that worked to distort and tamper with familiar practices of looking. I looped hours of film that I left running throughout the day, set up on a monitor in the corner of my home office. In this sense, I avoided direct observation and unshackled from the burgeoning responsibility of having to 'theme' hours of video into useful categories or not. Through this alternative mode of spectatorship, the content of the video began to perform in strange and intriguing ways within my peripheral vision. This felt slightly uncomfortable and odd, as I busied myself with other activities, such as reading, writing and skype conversations with colleagues. I became more attuned to the various flickers, sounds and movements emanating that caught my attention in moments of slippage, false starts and re-routes within the action. The 
children's gestures into the camera drew my attention in ways that I could not have predicted. I found amusement in their care-free attitudes towards the filming process, which ultimately resonated as I too became more 'care free' about the responsibility of having to frame events according to social perspectives of the child. These moments became innovative sites of collaboration between human (child / researcher) and machine (camera / digital video) that disturbed something of my comfortable researcher 'gaze'. However, "perhaps a cautionary note would be that perhaps these sites simultaneously conspired to re-frame and re-articulate once again" (Holmes, 2010, p. 34). I suggest then, what becomes paramount within this destabilising process, at the overlap of human and digital relations, is to attune to moments of misrecognition, contemplation and tensions as sites of knowledge production.

From approximately 40 hours of video footage, played on loop as described above, this paper draws on a series of still frames that I have gathered through this unorthodox technique. As discussed, entangling my own gaze with the video footage in this way, helped to decentre human subjectivities (researcher / child) whilst offering a way to recognise how the material (digital) had agency in what was said and done. The still frames presented take on a special significance and offer a change in direction that registers the uneasy, untimely and non-linear, as a route to understanding the lively intervals within the event through a new singularity.

The technique operates in conjunction with digital experiments with source still frames, where I theorise the film as affective forces in a complex arrangement of bodies (human and otherwise). For example, distorting source still frames to foreground light, colour, patterns and texture offers a way to engage with the indigestibility of those more indiscernible, peculiar or hard to place sequences of action. Therefore, the video analysis extends beyond simply labelling the child and their capacities in new and alternate ways, as video data sensing attempts to complicate humanistic notions of joy, harmony, surprise and cheekiness, to recognise how child subjectivities emerge out of the movements and rhythms of bodies, formlessness and chaos.

I hesitate to call these practices a methodological process to effectively grapple with large quantities of digital data as it is neither governed by rules or procedures and nor is it meant to be orderly within a post qualitative approach. However, I realise the importance of articulating how I experimented with the digital footage and subsequently in doing so, re attuned to the 'doing' (St Pierre, 2013) of video per se. Through this experimental process in attempting to decentre human subjectivities, I

VIDEO JOURNAL OF EDUCATION AND PEDAGOGY 4 (2O19) $\quad$ 1-22 
reflect upon "what (I) might (have) resisted or let fall away" (Hofsess and Thiel, 2017, p. 46). As such, the wonderment of what might become possible in my ongoing entanglements with the video phenomena (Maclure, 2013) becomes fruitful in avoiding the pursuit of the 'whole' story of full / partial 'truths' (MacLure, 2005).

In the next section, I provide a brief topology of contemporary post qualitative work with children in visual based inquiry. This work is important to understand how freeing oneself from existing qualitative paradigms and persisting in the mess (Lather, 2009) of a dislocating take on 'reality' and 'truth' prompts new modes of engagement with child subjectivities in video research.

\section{$2 \quad$ Mapping Contemporary Work with Children and Video, in Post Qualitative Inquiry}

My intention is to draw on post qualitative inquiry that uses insights from the pragmatic philosophy of Deleuze and Guattari (1987/2014) to enable something more to be said about children's lives within community and educational settings. Such work often creates less clarity and understanding and this has important implications for the field of education and childhood studies.

The coming studies are important as they question the 'relative humanness of child'; that seek to re-think child subjectivity as a "transgressive counter-image (...) neither as prospective saviour nor as victim" (Lenz Taguchi, Palmer and Gustafsson, 2016, p. 707). The paper permits moments where we might pause and imagine new sites of identity that disturb something of our comfortable gaze and those entrenched categorisations of children. What emerges, is the figure of the child and researcher as a creation of potentialities that break free from normativity to become productive in providing a somewhat 'less constrained' position (Olsson, 2009) when working with human subjectivities at the fringes of video based inquiry.

I have been inspired by de Freitas (2015), who highlights the dominant approaches to dealing with video in educational research, tends to focus on "viewing the video attentively, describing the data, identifying critical events, transcribing, coding, constructing a storyline, and composing the narrative" (2015, p. 413). The author points to a new kind of video research that connects with the body in radically new ways, by highlighting the dichotomies at play between 'the non-thinking body' and those advocating for 'embodied 
cognition', or the thinking body. This work has remained integral, because it helps to understand video in educational research, which proliferates from a different perspective that situates within the history of scientific cinema. This perspective recognises the ontologies that underpin the dominant approaches to making and watching film, in doing so, proposes an alternative way of working with video data. The author's work draws on Deleuze's notion of the 'time-image' (1989) that helps to think beyond normative visual perceptions in classroom video inquiry. The aim of de Freitas work (2015) was to generate a "dynamic diagram for (...) moments in classroom interaction" that slowly built layers upon each source image and that offered "a way to tap into a new dimension for each "frame" (2015, p. 325). The study offers an inventive yet pragmatic approach in visually translating the materiality of 'learning assemblages' (de Freitas and Palmer, 2016) through digital experimentation with light and shade. Such experiments foreground digital software as an unlikely component in illuminating other hidden performative entities in video research, as I later draw upon.

Next, I highlight studies that have attempted to work with visual data and children in non-representational ways, yet, such studies, I suggest, are not dealing with the challenge of large visual data sets and are different from de Freitas (2015) work embedded in early cinema. Otterstad and Waterhouse (2016), move beyond fixed narratives of child/ren and childhoods in order to disrupt the adult / child binary. They use Barad (2014) by undertaking a 'cutting-together-apart' of childhood photographs which allows them to explore the machinery that produces the categories of child/ren that find meaning through their bodies and faces. What their work illustrates is the repercussions, especially the benefits when a different logic that welcomes sensation, affect and intensities, is used to understand visual materials of children. I draw parallels with Ulmer's, (2015) work who presents a series of photographs as hypermodal assemblages, where interconnected layers of sound, text and images are re-imagined as 'thresholds of prohibitive passageways' (2015, p. 177). Such conversations are effective in contemplating how source visual data can be manipulated to increase the attentiveness to the things, artefacts and surroundings that can otherwise be overlooked in favour of language and interpersonal relations.

Contemporary work by Ivinson and Renold's (2016) offers a way to consider the camera as a 'post human participant' (2016, p. 169). Their research explored young people's experiences of growing up in a postindustrial Welsh mining town. What becomes productive is how the camera angles worked to displace the threatening male gaze that had dominated the

VIDEO JOURNAL OF EDUCATION AND PEDAGOGY 4 (2O19) $\mathbf{1 - 2 2}$ 
young girls' ways of knowing their bodies in the community, replacing it with a specific and purposeful gaze of the girls' own choosing. The camera formed a crucial performative role in a more-than-human assemblage that created "a new experience of moving (...) allowing the girls to be released of their bodies" (2016, p. 180) and the "objectifying male gaze that kept the girls' bodies in place" (2016, p. 180). This work is useful to consider how the GoPro camera angles shape the ebbs and flows in order to rupture the objectifying researcher gaze. Holmes (2010) examines critical methodological issues when working at the intersection of film, education research and visual cultures. Holmes draws from observations of children in classrooms and representations of children in film to push against 'familiar framing practices that embrace some and prohibit other ways of seeing' (2010, p. 2). As such my work with GoPro cameras and the digital footage produced works to "evoke disruptions to stability (...) in order to explore ways we might (dis)possess when we observe children" (2010, p. 4).

Jones, Holmes, MacRae and MacLure (2010) challenge researchers to force their 'video vision to jam or break' (2010, p. 544) and, embrace "a more open array of responses (...) less burdened with the weight of prior assumptions" (2010, p. 547). MacLure (2010) discusses how to alternately engage with ethnographic 'data' (video and field-notes) produced in an early years project. MacLure highlights the fragments of 'data' selected began as a kind of 'glow', in moments that provoked the research team to recollect and animate stories from the field with children. These studies offer a starting point to engage with visual material beyond representational modes of enquiry. However, what these studies do not address is how to productively deal with vast quantities of digital video, in the pursuit of radically reconceiving the nature of video research with children.

The literature above presents a number of challenges to researchers working with visual data and children, namely how to recognise video data as performative rather than representational. In the next section, I take up these challenges in my own research, grappling with how to engage post qualitatively with large quantities of video data in a productive manner. My aim is to disrupt arborescent, hierarchically arranged systems, where thought always places the human subject and her concerns 'above' those of 'otherthan-human' worlds (Taylor and Hughes, 2016). I discuss how Video Data sensing, works through a 'flattened' and open-ended process to open the child, camera and researcher 'assemblage' (Deleuze and Guattari, 1987/2014) to new becomings. 
Video Data Sensing: Working Post Qualitatively with Large Quantities of Visual Data

During my doctoral study, an issue began to emerge, in relation to the vast quantities of digital footage produced when both the children and I often found ourselves experimenting with the GoPro device that was equally worn, mounted or incorporated into the action in a number of ways (Caton and Hackett, 2019). Due to the camera's digital capacity to record and save extended sequences of film, I very quickly accrued hours of high definition footage with no idea how to make sense of obscurities, indiscernibility and non-linear shots that dominated the filming process but intrigued me in surprising ways. I became preoccupied wondering what to do with the vast quantities of digital film the children frequently produced, during each visit to the school. I often interjected in the filming process, whereby I would start and stop the recordings on the GoPro device whilst the children were wearing the camera attached to a body harness. I did so, in accordance with my adult perspective over the action. I became preoccupied, accounting for children's exchanges and dalliances according to suitability or not. As such, I missed, whilst in the field, opportunities to deeply engage with how the children and I, became swept up in moments of slippage, regular detours and reroutes that took the filming in new directions. This seemingly positivist and thematic approach to the videoing, provoked me to question its worth and value within a post qualitative framing that no longer seemed to resonate.

I took account of the content and quantity of the video produced that was useful and plentiful, yet the content and quantity of the video became less of a focus over time and more of a distraction. I began to wonder how to work productively with the video footage, beyond codification and habitualised ways I once observed the children and their behaviours. As such, it no longer made sense to note specific time sequences or subdivide fragments of video into categories that related to its usefulness. Instead, recognising the 'doing' (St Pierre, 2011) of the research, and what I was 'doing' whilst, in the field or later whilst watching the video back became an alternative focus. I reattuned to the 'doing' of video from the inside (Barad, 2007) as part of a 'researcher-camera-child' assemblage (Deleuze and Guattari, 1987/2014), whereby the 'gathering' and the 'analytical' process became retelling of a different kind.

Whilst at home, grappling with large quantities of footage produced in the field, I recognised the choices made to foreground certain sequences of film over others that emerged in moments that drew my "attention across the

VIDEO JOURNAL OF EDUCATION AND PEDAGOGY 4 (2O19) $\quad \mathbf{1 - 2 2}$ 
surface of the screen (...), intensifying (my) gaze” (MacLure, 2010, p. 282). MacLure (2010) along with colleagues working in an early years project, struggled with quantities of ethnographic 'data' (videos and field-notes). Often in conversation with the research team, the 'data' would catch their attention and its beginnings would produce a kind of 'glow' that fired up conversations, as they began to recall incidents and details in the project classroom. MacLure (2010) did not experiment with digital technology to find the 'glow' and as such, the 'glow' as a conceptual tool, works differently in this paper to theorise how the still frames emerged from the masses of footage playing on a loop. For example, rather than watching hours of footage in a linear and divisive manner, I digitally experimented with the visual/audio software in which the footage was saved. Using the capacities of the software, I frequently left the video on a loop, yet, I also skipped over and/or sped the video through moments of disinterest, pausing to slow down or stop at those fragments of video that 'started to glimmer' (MacLure, 2010). I often pondered on the specific qualities of the video that drew my attention in this manner, since I was not able to "recognise an example right at the point of its emergence" (MacLure, 2010, p. 282). However, drawing from MacLure's original theorisations of 'data' that 'glow', the fragments worked beyond the specific content of the image, instead making connections and 're-animating' my experiences of filming with the children. In this sense, I was unable to pre-plan how the video footage would work on me in these strange and surprising ways. The video footage incited an intensity that acted beyond its immediate content and context, 'that generated sensations resonating in (my) body as well as the brain' (2010, p. 282) that coerced a closer look into the phenomena at hand.

I have tried to keep my eye on the miniscule and rather overlooked moments in which I was undone by the process of watching the video. I have attempted to engage with the indigestibility of watching long sequences of video that remained blurred, inverted or framed extreme close ups of body parts and material objects (as is often the case with video footage recorded on wearable cameras in particular). Remaining with the content as it unfolded demonstrated a persistence and patience that was key to the process of video data sensing (Caton, 2019). In this sense, the material agency of digital film coerced a response in unexpected and intriguing ways.

My work with the go pro cameras and the children seeks to resolutely, refute general ideas or models of what constitutes familiar objects and behaviours of the children that we 'see'. For example, writing 'thick descriptions' (Geertz, 1973) of the activities in the classroom would be antithetical, as it would re-produce the children as knowing / known and 
coherent subjects that are grounded in humanist perceptions. The still frames that emerge through the process of looping the video and experimenting with the possibilities of speeding up and slowing down the footage, operate as lively intervals or flickers that resist codification or categorisation. They are productive sites of human and machine entanglements.

\section{4 \\ Digital Experiments with Source Still Frames}

In the coming section, I present a series of source images that emerged through the unorthodox mode of video spectatorship, whereby, I looped extended sequences of film on a monitor out of direct view. I was unable to pre-plan how the video footage would work on me in these strange and surprising ways. The frames, offer rare fragments that operated beyond the specific content of the image, where I made connections that re-animated my experiences of filming with the children.

I continue to experiment with the source footage, to foreground light, shade, texture, patterns and colour as a way to unravel theoretical insight and evoke a relation with the lived experience.

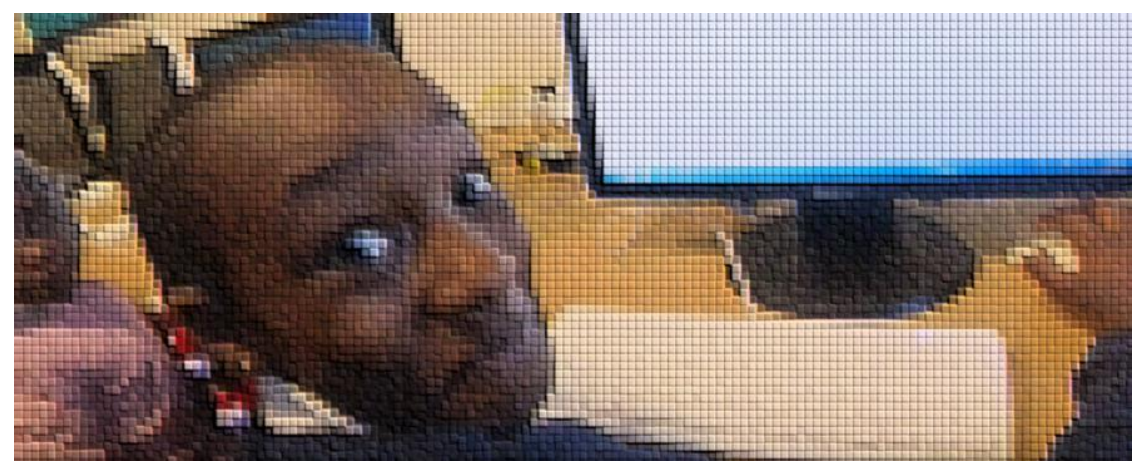

FIGURE 1 Child-Camera-Digital Assemblage $1 \#$

To create the pixelated images, I experimented with Microsoft Paint digital software, widely accessible and often used to enhance visual material in public and private domains. The aim of the experiment was to incite a 'haptic eye' (Marks, 2002), by focussing on the potential of the digital pixels as performative entities. Colebrook (2014) explains; 
colour, occurs as relation between waves of light and an organism's eye, but the eye, in turn, occurs as the relation between organic living matter, milieus of light, and evolutionary tendencies towards formation.

COLEBROOK, 2O14:244

Working with digital video in this experimental way helps to resist interpretation and familiar modes of classifying the children and instead allows a glimpse into the making and unmaking of these phenomena that classifying does not offer (Hofsess, 2015). The series of experimental frames invite a 'haptic' visualisation and a route to re-think those socio-material entanglements with digital technology. Rose (2016) explains the 'haptic eye' is a term used to emphasise the way bodies can be experienced in new ways through close encounters with images. Marks (2002) offers the concept of 'haptic visuality' to foreground the way film can reach audiences through its materiality and 'through a contact between perceiver and object represented' (2002, p. xi). Marks suggests vision can be tactile, as if 'touching a film with one's eyes' (2002, p. xi).

Video data sensing works in conjunction with a 'haptic' sensibility that opens up other performative entities of light, shade, colour and texture. Integral to the process is recognising complex and open-ended human and digital relations. For example, we might question, how does the digital image shape what researcher responses become and equally how do researcher perceptions, intentions and desires shape what the digital image becomes. Through this process, my 'gaze' becomes haptic, attuning to the colour, texture and shades that are prominent and produced through ongoing experimentation with the digital software. This process of undoing the image creates knowledge, wonder and curiosity, which in turn, unpicks at the seams of the researcher 'gaze'. 


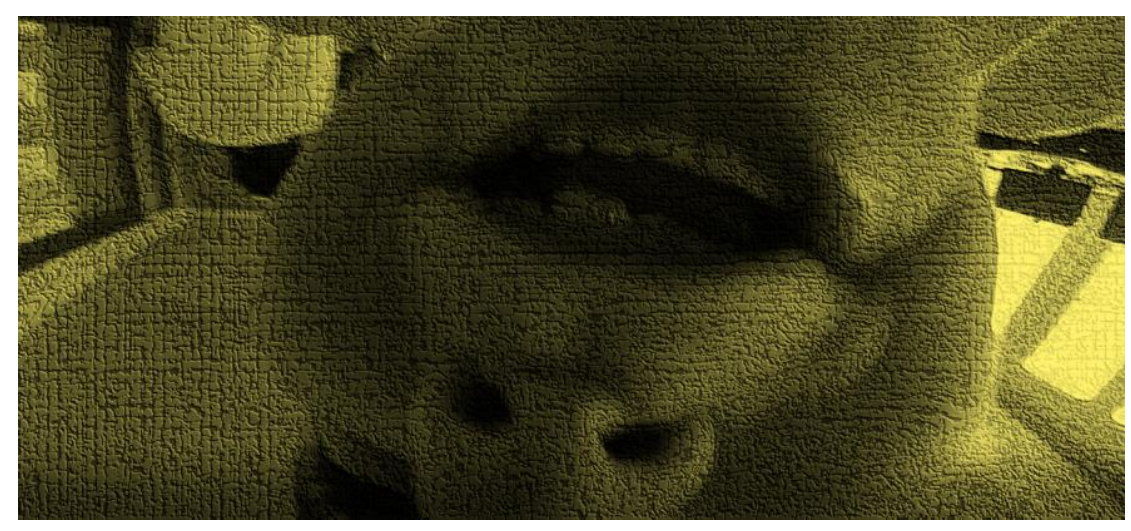

FIGURE 2 Child-Camera-Digital Assemblage 2\#

Video data sensing is a process that cannot be pinned down as a 'method' per se or triangulated, prescribed and repeated. Instead, through an embodied and sensory engagement incited by digital experiments with light, colour and texture, what emerges is not tied to the real but rather, captures some of the 'becoming-with', (Deleuze and Guattari, 1987/2014), where forces of the haptic provoke something elsewhere (Otterstad and Waterhouse, 2016).

I draw parallels with Ulmer's (2015) and Otterstad and Waterhouse (2016) work that pushes at entrenched representational approaches within qualitative inquiry to invite a playfulness and a very different response that disturbs any sense of a straightforward reading. For example, experimenting with the source video to see what effects it is capable of producing, without being constrained by what someone or something else (author, text or image) intended (Ulmer, 2015) provokes an individual and embodied response. The framing of this speculative research means we cannot know in advance what will emerge so it becomes important to recognise 'thresholds' (Ulmer, 2015) as sites of knowledge production. At 'thresholds' we might interrogate ideas and discursive framings that no longer seem to exits in isolation, as stories that hold still (Holmes, 2010).

Perhaps, video data sensing moves us toward something more like what Nordstrom (2017) theorizes as an anti-methodology in which the experimental and curatorial work with 'data' cannot be replicated, from study to study. Anti-methodology, is a useful concept, as it builds on post qualitative methodology to recognise a 'middle space' that is created between "reterritorializing forces (e.g., conventional qualitative inquiry) and 
deterritorializing forces (e.g., post structural and post human theories that throw positivist and interpretivist approaches into radical doubt)" (Nordstrom, 2018, p. 215).

In order to recognise a 'middle space' that emerges when attempting to traverse two ontological perspectives, I experiment with the video in a way that makes felt a different vibratory pattern each time I come to engage. For example, 'plugging into' (Jackson and Mazzei, 2012) the child-camera assemblage, I experience new sets of sensations and recollections of small incidents that 'stick out' that are curious, odd, enigmatic and surprising. These new encounters with the video provide me with a starting point to question what my researcher subjectivity might become in these new embodied entanglements with the video. The seemingly disparate worlds of film spectatorship and education video inquiry each bring interesting challenges to the idea of the child. However, my intentions have not been to bring film theory and education video practices over to the other but to disrupt each in order to produce new ways of seeing (Holmes, 2010). The next section, opens up the source footage to re-think entrenched video method/ological approaches in qualitative inquiry and the habits that surround, circumscribe what it means to think and know (Holmes, Jones and Osgood, 2018).

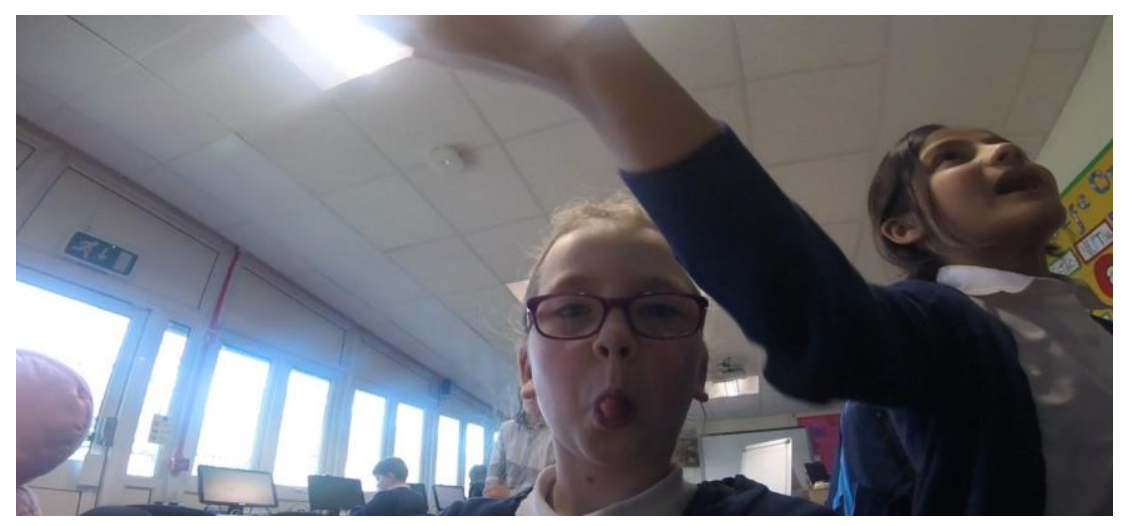

FIGURE 3 Child-Camera-Source Footage Assemblage $3^{\#}$

In source still frame (3\#), I begin by drawing on conventional, socio-cultural categories to discuss the young girl and her perceived gestures into the 
camera lens. The school girl is situated in a classroom and is in the midst of positioning the GoPro camera under the PC monitor, situated out of frame. Her face is central and relatively close to the camera, she sticks her tongue out to greet her fantasy audience in a characterful manner. I am immediately drawn to the tongue, thinking of associated wider discourses and behaviours (cheekiness, naughtiness, rebellion, humour) when children display their tongues to adults. Resisting an anthropocentric lens and not focusing on human centred agency and meaning, whilst looking at this image, is very difficult (Hultman and Lenz Taguchi, 2010).

Haraway (1988) reminds us that binaries reinforce hierarchical thinking, since there are two parts to the binary that sit in opposition. For example, the girl (above) gestures to the audience with her tongue stuck out; her tongue plays an important signifying role that associates with normative ideas regarding how children (and tongues?) ought to behave in school. The tongue in the image produces a powerful effect that might render the girl as cheeky and disrespectful, in some sense as exemplifying deviant behaviour in such school-based settings. I extend these arguments to suggest, in contrast, that an absence of the tongue may lead to us to automatically re categorising the girl as 'compliant' and 'respectful' that sits in stark dichotomy with the child as 'cheeky' or 'disrespectful'. The tongue thus becomes a powerful component in understanding the child and her behaviours. The image of the tongue alters how we respond and therefore operates within the image as a powerful signifier. The tongue is also an organ that sits at the forefront of language and the body and is integral to the production and synthesis of language and human communication. At the same time, it is a piece of flesh that reminds us of those embodied practices of language and the animal characteristics of our constitution. The girl is positioned within one of two binaries, 'compliant' or 'non-compliant, 'good' or 'bad', 'respectful' or 'disrespectful'. We make meaning based on the representation, foregrounding the child and her behaviours.

I navigate the tricky terrain where global narratives in relation to children's progress, development and economics are at risk of being frequently (re) produced in education video research (Flewitt, 2006, Selwyn, 2016). However, whilst discourses around progress and development are dominant, they can be challenged; this challenge requires "dislocating, displacing, and dislodging habits including habits of thought" (Holmes, Jones and Osgood, 2018, p. 2).

I demonstrate the need to queer such habits of thought in education video research, by taking matter and materiality as a starting place and decentring the child in the action. I do this through digital experiments with light, shade

VIDEO JOURNAL OF EDUCATION AND PEDAGOGY 4 (2O19) $\quad \mathbf{1 - 2 2}$ 
and texture manipulated within source video material, as previously discussed. I suggest, this process offers one route to claiming knowledge and to 'think harder about the status of human subjectivity, ethical relations, norms and values (Braidotti, 2013, p. 186) and to understand what a body might become in new entanglements with the digital.

6 Opening up the Child-camera Assemblage beyond Representation

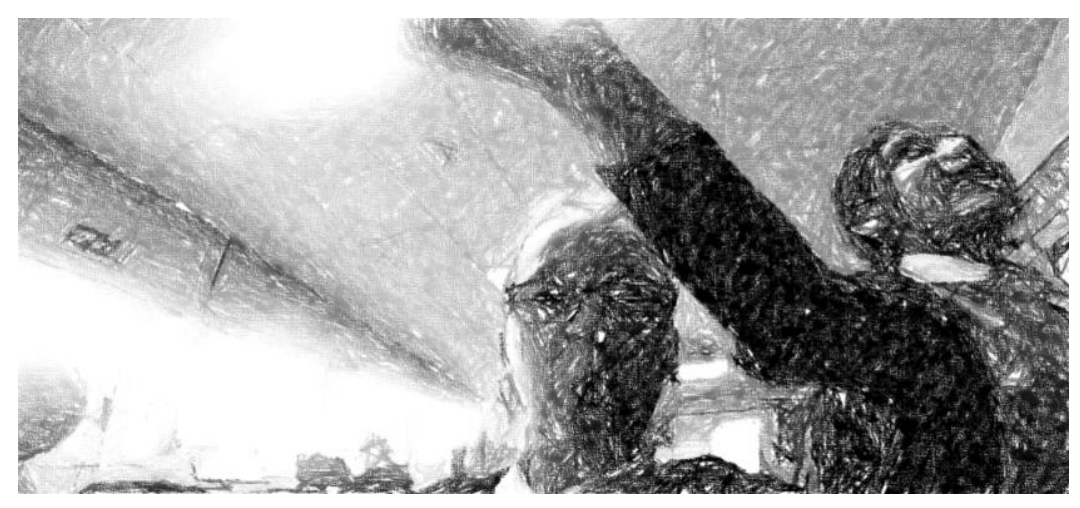

FIGURE 4 Child-Camera-Digital Assemblage 4\#

Deleuze and Guattari (1987/2014) explain that the focus within any assemblage is not on specific functionalities of the single components it is in the coming together of the components that new understandings are produced. For example, in the source image $\left(3^{\#)}\right.$ we see girl, tongue, school uniform, windows, arm, polystyrene celling etc. It is too easy to attach associated discourses and values to all of the objects and bodies we see. Instead, experiments with the digital pixels in image $\left(4^{\#}\right)$ offer a way to consider what other potentials and associations are incited through the arrangement of those singular non-human entities coming together. We must resist the temptation to account for the specifics of the girl pulling her tongue out; this would mean 'asking what the image means?' Instead, I ask 'what the image does?', in these new experiments with digital software.

The key is to recognise the fragments of footage that emerged from vast quantities of source material, as performative rather than representational. The fragments operate through an embodied and sensory mode of engagement that are opened up, through the passage of a haptic vision. Haptic vision differs from conventional optical vision that we often use to recognise objects, children and their surroundings within educational video. 
For example, in the source image $\left(3^{\#)}\right.$ the action privileges familiar discursive inscriptions pertaining to a classroom, for example, school uniform, generic white ceiling tiles, computers, white board, cheeky and inquisitive children. Our optic vision operates at a distance and allows us to perceive objects in space, privileging the 'representational power of the image' (Marks, 200o, p. 163). Alternatively, haptic vision incited through the digital experiments with the pixels, image $\left(4^{\#}\right)$, coerces our gaze to move over the 'surface of the screen', appealing to tactile connections. Marks explains that the eyes function like 'organs of touch', whereby the physical objects are given up and instead "resolve into figuration gradually (...) privileging the material presence of the image" (Marks, 2000, p. 163).

The pixelated experiments draw on colour, shadows, objects and bodies within the source image that help us to perceive an alternative route to sensing the children's other entanglements with matter and materials. The experiments with the digital pixels work to produce questions based on what bodies might be able to do in a new configuration. We may perceive the initial source image $\left(3^{\#}\right)$ as a route to understanding the solutions to certain problems or questions. For example, how the children perform their subjects, manage their desires and behaviours in the context of the classroom. To critique some of the mundane practices and attend to habitual ways of thinking, I draw on Colebrook, who suggests heterogeneous connections help to 're-compose the problems that orient the self, counteractualizing the present by drawing on the pure past of the questions from which we have emerged' (2014, p. 249). The technique of video data sensing provides a sensory and embodied way to consider how the children, GoPro camera, and researcher are mutually "imbricated with the becoming of the concept" (de Freitas and Palmer, 2016, p. 1218), which moves beyond perpetuating the familiar through questions that already contain the answer (Deleuze and Guattari, 1987/2014). Installing into a haptic vision of the world is one practical technique to trace the overlap of concept and method that activates the differential and 'holds difference in lively suspension' (Manning and Massumi, 2015, p. 3).

The young girl in image $\left(4^{\#}\right)$ becomes almost indiscernible in these new digital experiments and her tongue is unrecognisable. The shadow of a limb outstretched above seems to float, as bodies, desires and materials all partake through the forces of the 'child-camera' assemblage (Deleuze and Guattari, 1987/2014) where difference is held 'in lively suspension' (Manning and Massumi, 2015) as a cite for knowledge production. I wonder what the activation of differentials opens up in knowing the child through a new digital reconfiguration of a body that is free from those wider associations

VIDEO JOURNAL OF EDUCATION AND PEDAGOGY 4 (2O19) $\quad \mathbf{1 - 2 2}$ 
and framing practices of observing children. The potential of the digital pixels allow us to engage with a new set of sensations, which are utile in dissolving the 'conventional' child in such a school-based scenario. This offers a route to an alternative mode of understanding that liberates children from those precise and determined functions that are often installed through the practice of looking. For example, image $\left(4^{\#)}\right.$ operates to re-position the child as 'other' (Murris, 2016) in new acts of mind and body that resist entire systems of social referencing. Such visual experiments are useful in recognising how 'normativity' positions certain bodies and minds over others, and is helpful in destabilising socially constructed perceptions of 'life' and 'being'. For example, the children might be encouraged to see themselves in multiple assemblages that create and perform a body that is always in motion and is never final 'but engages in exploring new and other possibilities of what a body assemblage can do' (Lenz Taguchi et al., 2016, p. 710), what a child can do and become.

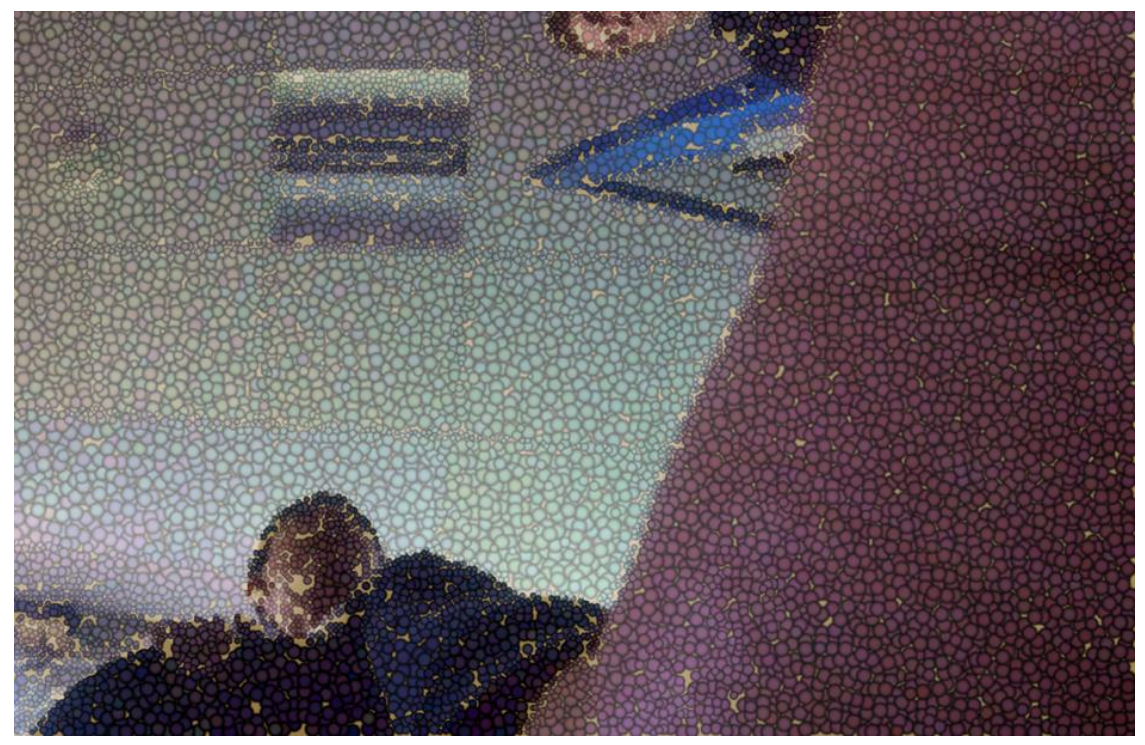

FIGURE 5 Child-Camera-Digital Assemblage $5^{\#}$

Continuing to draw from the children's practices with the GoPro camera, I present frame $\left(5^{\#)}\right.$ as a way of further dismantling the process of 'looking' and that which is ordinarily and habitually attached to the process of 'observing' children. The child, door, ceiling and teacher $\left(5^{\#)}\right.$ take on another form where textures, shapes, colours and patterns become 'entangled with parts other than our eyes' (Holmes et al, 2018). The tactile aesthetics have 
jolted me into a conceptual space that questions the social referencing on which my practices of looking are based' (Holmes, 2010, p. 32).

The human subjects, objects and materials in view become relationally distinct and no longer seem to exist as separate individual entities. What is perceptible are those other hidden performative entities of light, shade, depth and texture that entangle with the human body and the digital capacities of the software. As previously discussed, I draw on Marks' discussion of 'haptic visuality', by "making vision multisensory (...) refusing to make (...) images accessible to vision" (2000, p. 162), so that the viewer must resort to other senses, such as touch, in order to perceive the image.

My recollections have been embellished, altered, tampered with and edited in the process of recounting, however, instead of subjecting myself and the children to detailed critical analysis, I have tried to retain some of the indigestibility of these experiences. For example, by leaving these nonlinear and peculiar frames in they have helped me to interrupt myself or throw myself off subject, especially my own tendency to be drawn back to the relative safety of qualitative and habitual approaches. The series of images $\left(1 \#, 2^{\#}, 4^{\#,} 5^{\#)}\right.$ open up multiple and experimental ways of (not) knowing and so resit critique and the tendency to 'get stuck' in familiar modes of thinking and doing research with video. As such, the images might just offer some of those disruptive moments to make change possible.

\section{$7 \quad$ Conclusion}

Working at the interstices of post qualitative inquiry and child participatory video research, this study responded to the need for more work around child participatory video recognised through a non-hierarchical arrangement of the world, where bodies (human and otherwise) coexist and agency is not bounded in one human subject.

The paper has described practices and approaches I took up, for working post qualitatively with vast amounts of digital footage, experimenting with how to grapple and think through/with/in video produced. The technique of video data sensing (Caton, 2019) opens up a way to deeply engage and begin to re-imagine our habitual, safe behaviours and further interrogate how video based inquiry with children is "always already inscribed with discrete discursive framings" (Holmes, 2010, p. 33).

My study is amongst a growing number (de Freitas, 2015, 2016, Otterstad and Waterhouse, 2016, Ivinson and Renolds, 2016, Jones, Holmes, MacRae and MacLure, 2010, Holmes, 2010) of studies working post qualitatively with

VIDEO JOURNAL OF EDUCATION AND PEDAGOGY 4 (2O19) $\quad$ 1-22 
children in visual inquiry. As discussed, such studies begin to re-imagine human subjectivities, film, cameras and photographs without language and representational boundaries that serve to fix human subjectivities into place. This paper makes a contribution to this scope of work, by describing affective methodologies for dealing with vast amounts of video data whilst displacing dominant framings for knowing children. The key tenet has been to resist binary logic in order to highlight that we (researchers / practitioners) and child participants are always already entangled with, not separate from or superior to matter (St Pierre, 2013). As such, this work questions the usefulness of criticality and the role of humanist qualitative approaches, in video inquiry with children that continue to fall short.

I conclude, in wondering to what extent this paper will produce further and alternative differentiations that will come to 'matter' for children and researchers involved in post qualitative video inquiry. Perhaps, the question might not be answered immediately on these pages, but, as an emergent journey, set into motion through the different kinds of assemblages, video data sensing is put to work and re-worked.

\section{References}

Barad, K. (2007). Meeting the Universe Halfway, Duke University Press, USA.

Barad, K. (2014). Diffracting diffraction: Cutting together - apart, Parallax, Vol 20 (3) pp, $168-187$.

Braidotti, R. (2013). Post Humanities, European Education Research Journal, Vol 12 (1), pp. $1-19$.

Caton, L. (2019). Becoming Researcher: Navigating a post-qualitative inquiry involving child participants and wearable action cameras, $\mathrm{PhD}$ Thesis, Manchester Metropolitan University, Manchester, UK.

Caton, L \& Hackett, A (2019) Head mounted, chest mounted, tripod or roaming? Ontological possibilities for doing visual research with children and GoPro cameras, in The Routledge International Handbook of Learning with Technology in Early Childhood, Kucirkova, N., Rowsell, J. \& Falloon, G. (eds.), London: Routledge.

Colebrook, C. (2014). Sex after Life: Essays on extinction, Vol 2. Michigan: Open Humanities Press.

de Freitas, E. (2015). 'Classroom Video Data and the Time-Image: An-Archiving the Student Body.' Deleuze Studies, 9(3) pp. 318-336.

de Freitas, E. (2016). 'The moving image in education research: Reassembling the body in classroom video data.' International Journal of Qualitative Studies in Education, 29(4) pp. 553-572.

VIDEO JOURNAL OF EDUCATION AND PEDAGOGY 4 (2019) $\quad$ 1-22 
de Freitas, E. and Palmer, A. (2015). 'How scientific concepts come to matter in early childhood curriculum: rethinking the concept of force.' Cultural Studies of Scientific Education, 11 pp. 1201-1222.

Deleuze, G. and Guattari, F. (1987/2014). A Thousand Plateaus. London, New York: Bloomsbury Academic.

Flewitt, R. (2006). Using video to investigate preschool classroom interaction: education research assumptions and methodological practices. Visual Communication, 5(1), 25-50.

Geertz, C. (1973). The Interpretation of Cultures, New York: Basic Books

Haraway, D. (1988). 'Situated Knowledges: The Science Question in Feminism and the Privilege of Partial Perspective.' Feminist Studies, 14(3) pp. 575-599.

Hofsess, B. (2015). Do With Me: The Action Orient of Aesthetic Experimental Play, Visual Arts Research, Vol 41 (2) pp. 1-17.

Hofsess, B. A., \& Thiel, J. J. (2017). Pause/Play: Curating as Living/Aesthetic Analysis. Reconceptualizing Educational Research Methodology, Vol 8(3), pp. $3^{1-} 5^{2}$.

Holmes, R. (2010). Cinemaethnographic Specta(c)torship: Discursive Readings of What We Choose to (Dis)possess. Cultural Studies $\leftrightarrow$ Critical Methodologies, 10(3), 221-237.

Holmes, R., Jones, L., Osgood, J. (2018). Mundane Habits, Ordinary Affects, and Methodological Creations, in Research Handbook on Childhood nature, A. CutterMackenzie et al. (eds.), Springer International Publishing: Switzerland.

Hultman, K. and Lenz Taguchi, H. (2010). 'Challenging anthropocentric analysis of visual data: a relational materialist methodological approach to educational research.' International Journal of Qualitative Studies in Education, 23(5) pp. 525542.

Ivinson, G. and Renold, E. (2016). 'Girls, Camera, (Intra) Action: Mapping Posthuman Possibilities in a Diffractive Analysis of Camera-Girl Assemblages in Research on Gender, Corporeality and Place', in Post-human Research practices in Education, Taylor, C. and Hughes, C. (eds.). Basingstoke: Palgrave Macmillan, pp. 168-185.

Jones, L., Holmes, R., MacRae, C. and Maclure, M. (2010). 'Documenting classroom life: how can I write about what I am seeing?' Qualitative Research, 10(4) pp. 479491.

Lenz Taguchi, H., Palmer, A. and Gustaffson, L. (2016). 'Individuating "sparks" and "flickers" of "a life" in dance practices with preschoolers: the "monstrous child" of Colebrook's Queer Vitalism.' Discourse: Studies in the Cultural Politics of Education, 37(5) pp. 705-716.

MacLure, M. (2005). 'The Wonder of Method'. Unpublished paper.

MacLure, M. (2010). 'The offence of theory.' Journal of Education Policy, 25(2) pp. 277286.

VIDEO JOURNAL OF EDUCATION AND PEDAGOGY 4 (2O19) $\quad$ 1-22 
MacLure, M. (2011). Qualitative Inquiry: Where Are the Ruins? Qualitative Inquiry, 17(10), 997-1005.

MacLure, M. (2013). Researching without representation? Language and materiality in post-qualitative methodology. International Journal of Qualitative Studies in Education, Vol 26 (6), pp. $658-667$.

Manning, E. and Massumi, B. (2015). 'Toward a Process Seed Bank: What ResearchCreation Can Do.' Journal of the New Media Caucus, 11(3).

Marks, L. (2000). The Skin of the Film, Intercultural Cinema, Embodiment, And The Senses. USA: Sage.

Marks, L. (2002). Touch, Sensuous Theory and Multisensory Media, Minneapolis: University of Minnesota Press

Murris, K. (2016). The Posthuman Child - Educational transformation through philosophy with picture books. London: Routledge.

Olsson, L. M. (2009). Movement and experimentation in young children's learning: Deleuze and Guattari in early childhood education. London: Routledge.

Otterstad, A. M. and Waterhouse, A. L. (2016). Beyond regimes of signs: making art/istic portrayals of haptic moments/movements with child/ren/hood, Discourse: Studies in the Cultural Politics of Education, Volume 37, Issue 5 pg 739753.

Pillow, W. (2003). Confession, Catharsis, or Cure? Rethinking the uses of reflexivity as methodological power in qualitative research, International Journal of Qualitative Studies in Education, Vol 19 (2) pp. 175- 196.

Rose, G. (2010). Doing Family Photography: The Domestic, the Public, the Politics of Sentiment. London: Routledge.

Rose, G (2016) Visual Methodologies: An Introduction to Researching with Visual Materials, $4^{\text {th }}$ Edition, London: Sage

Rosiek, J. (2013). 'Pragmatism and Post-Qualitative Futures.' International Journal of Post-Qualitative Studies in Education, 26(6) pp. 692-705.

Selwyn, N. (2016). Education and Technology, Key Issues and Debates, 2nd Ed. London: Bloomsbury.

St. Pierre, E. A. (2011). Anything can happen and does, Cultural Studies $\leftrightarrow$ Critical Methodologies, Vol 11 (4) pp. $386-389$

St. Pierre, E. A. (2013). The posts continue: becoming, International Journal of Qualitative Studies in Education, 26:6, 646-657.

Taylor, C. and Hughes, C. (2016). Posthuman research practices in Education. Basingstoke: Palgrave Macmillian.

Ulmer (2015). Photography Interrupted: A Hypermodal Assemblage, Qualitative Inquiry, Vol 22 (3), pg 176-182. 